\title{
Hierarchy curriculum for practical skills training in optics and photonics
}

XiaoDong Zheng, XiaoPing Wang, Xu Liu, XiangDong Liu, YuanFang Lin

XiaoDong Zheng, XiaoPing Wang, Xu Liu, XiangDong Liu, YuanFang Lin, "Hierarchy curriculum for practical skills training in optics and photonics," Proc. SPIE 10452, 14th Conference on Education and Training in Optics and Photonics: ETOP 2017, 104520F (16 August 2017); doi: 10.1117/12.2269491

SPIE Event: 14th Conference on Education and Training in Optics and Photonics, ETOP 2017, 2017, Hangzhou, China 


\title{
Hierarchy curriculum for practical skills training in optics and photonics
}

\author{
XiaoDong Zheng*, XiaoPing Wang, Xu Liu, XiangDong Liu, YuanFang Lin \\ College of Optical Science and Engineering, Zhejiang University, Hangzhou, China 310027
}

\begin{abstract}
The employers in optical engineering fields hope to recruit students who are capable of applying optical principles to solve engineering problems and have strong laboratory skills. In Zhejiang University, a hierarchy curriculum for practical skill training has been constructed to satisfy this demand. This curriculum includes "Introductive practicum" for freshmen, "Opto-mechanical systems design", "Engineering training", "Electronic system design", "Student research training program (SRTP)", "National University Students' Optical-Science-Technology Competition game", and "Offcampus externship". Without cutting optical theory credit hours, this hierarchy curriculum provides a step-by-step solution to enhance students' practical skills. By following such a hierarchy curriculum, students can smoothly advance from a novice to a qualified professional expert in optics. They will be able to utilize optical engineering tools to design, build, analyze, improve, and test systems, and will be able to work effectively in teams to solve problems in engineering and design.
\end{abstract}

Keywords: Curriculum, Practicum, Optics education, Practical skill, Training

\section{INTRODUCTION}

In the 21 century, technology and industry are developing faster and faster. Young students often quit their first job for a higher-paid position after they gain some working experience. This phenomenon makes employers reluctant to invest human and finance resources in training new employees. Employers in China hope that employed college graduates can play their role in the workforce immediately with minor vocational training. Whether this is a reasonable decision to make, this situation is the social reality we are currently facing. Another issue in optical and photonics engineering education is that students master practical skills related to optical engineering slower than those in other fields. In other words, optics learners usually face a learning curve with a low slope. To address these issues, practicums provide the perfect opportunities for students to gain professionalism.

In China, high school students must take part in a very competitive examination i.e. "Gaokao" for college admission and most of the students are the only child of their family. Practical skills training are not taken seriously in high school, and the faculty of Chinese Universities must face this problem.

In the past, practicums in the overall curriculum are insignificant. The only purpose of practicums was to improve students' hands-on ability. Based on the surveys conducted on college graduates and employers, the training in practical skills is still a "short board" in optical engineering education. How should we improve the curriculum? After many discussions, the teaching committee of college of optical science and engineering of Zhejiang University (ZJU) have eventually decided that summer break may be the best time for setting some additional practicum programs. Since there is no specific curriculum for the summer time, we can break through the limitations of the old curriculum, and provide more comprehensive and liberal training programs for the students.

To help students learn practical skills that are needed for future optical engineering and photonics related employment, we have designed a curriculum called the hierarchy curriculum. In this curriculum, different challenges are set for students to overcome. By tackling these challenges, students achieve more, understand how to cooperate with each other, learn to be grateful, and experience success.

Three years ago, the different practicums were scheduled in the curriculum for freshman, sophomore and senior year students. During sophomore and senior year, the student research training program (SRTP) takes place, and about $90 \%$ student chose to join the program as an initial research practice. Every two years, China national-wide university Students' Optical-Science-Technology Competition game (SOSTC) is held for sophomore and junior students.

14th Conference on Education and Training in Optics and Photonics: ETOP 2017, edited by Xu Liu,

Xi-Cheng Zhang, Proc. of SPIE Vol. 10452, 104520F · @ 2017 ICO, IEEE, OSA, SPIE

CCC code: $0277-786 \mathrm{X} / 17 / \$ 18 \cdot$ doi: $10.1117 / 12.2269491$ 


\section{DESIGN OF THE HIERARCHY CURRICULUM}

The students in ZJU usually declare their majors at the end of their freshman year. They start their major related curriculum from the start of their first summer break. The hierarchy curriculum for practical skills training begins from the first summer break and ends at the point of graduation.

The design of the whole plan has several goals: A. Design practicums that are diverse and suitable for students with different personal interests; B. Students have training activity to participate in every time period; C. Provide different paths for students with different career planning. Table 1 is the hierarchy curriculum for practical skills training in optics and photonics.

Table 1. Hierarchy curriculum for practical skills training in optics and photonics

\begin{tabular}{|l|l|l|l|l|}
\hline Student Year & Activity & Scheduled time & Credits & Duration \\
\hline Freshman & Major introductive practicum & First summer break & 1.0 & 1 week \\
\hline Freshman & Opto-Mechanical Systems Design & First summer break & 2.0 & 2 weeks \\
\hline Sophomore & Engineering training & Autumn-winter semester & 1.5 & 1 semester \\
\hline Sophomore & SRTP & Start from May of sophomore & $\begin{array}{l}4.0 \text { ( Non- } \\
\text { lecture) for } \\
\text { team leader, } \\
3.0 \text { for team } \\
\text { members }\end{array}$ & 1 year \\
\hline Sophomore & Electronics system design & Second summer break & 2 & 2 weeks \\
\hline Sophomore & Optical design project training & Second summer break & 2 & 2 weeks \\
\hline $\begin{array}{l}\text { Sophomore } \\
\text { or Junior }\end{array}$ & $\begin{array}{l}\text { National University Students' } \\
\text { Optical-Science-Technology } \\
\text { Competition game }\end{array}$ & Summer break & 0 & 1 year \\
\hline Junior & Off-campus externship & Third summer break & 2 & 3 weeks \\
\hline
\end{tabular}

\section{IMPLEMENTATIONS}

\subsection{Major introductive practicum for freshman}

"Major introductive practicum" for freshman is scheduled at the beginning of the student's first summer break. At this point, students have just confirmed their major and are very eager to understand what an optical engineering major can do in the future. Professional leaders, professors and senior students are invited to have orientation lectures to provide different points of view. After orientation lecture, one week of introductive practicum for optical engineering major is arranged. The introductive practicum contains 5 section contents:

A. Entertainment section: Student will use single-lens reflex digital cameras and 3D cameras; they will also apply optical sensing in computing games. This category is designed to help students understand the effects of various optical parameters, such as shutter speed, lens aperture, focus length etc. through hands on experience.

B. Experiential activity: Students will use various photoelectric sensors and infrared thermography to measure temperature distribution of human body; they will also use laser rangefinder to measure the heights of rooms and trees.

C. Hands-on production: the students will make a fiber jumper and evaluate its performance by themselves. 
D. Small contest: Students will design a solar cell powered toy car that can carry weights. Groups compete to use fewer batteries to ship more weights.

E. 3D printer assembly class: Students will assemble 3D printers themselves and print a simple model using their printer.

Each student should complete the projects of all 5 sections.

About 140 students are enrolled in the program each year, and they are divided into 5 group with about 28 students/group. Every group spends one day in one section and rotates to other sections in other days.

\subsection{Opto-Mechanical Systems Design}

"Opto-Mechanical Systems Design" is an introductive course for practical skill training. We use the Problem-Based Learning (PBL) method. We take commonly used optics products and optical components as design cases, and use SolidWorks design tools to study and design the basic opto-mechanical system structure. The main teaching contents are: optical parts holding mechanism, optical adjusting and moving mechanism, simple sheet metal and injection molding structure design, etc.

Optical design and mechanical design are the two stages of an optical problem. The optical system cannot exist independently without the mechanical structure. Though this class learning, students will be familiar with:

a. General design process of an opto-mechanical system. Students will begin by discussing conceptual designs and finally form all of the design documents.

b. The influence of environment on performance, the material of the opto-mechanical parts, and various typical optomechanical structures.

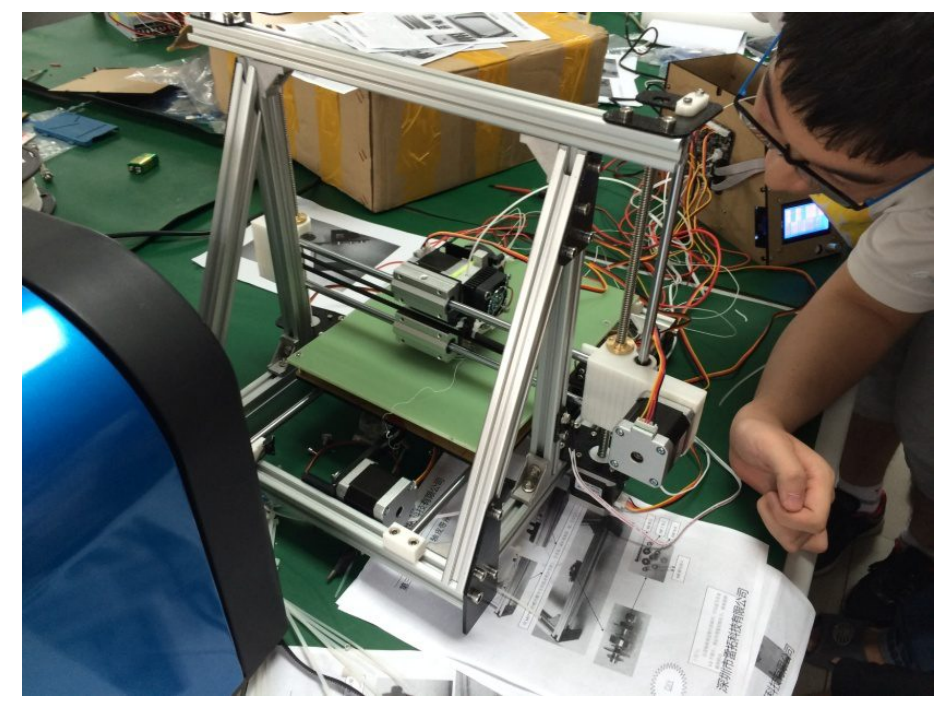

Fig. 1 Students assembling a 3D printer by themselves. 


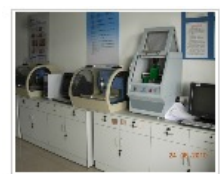

脆就机

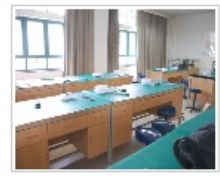

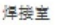

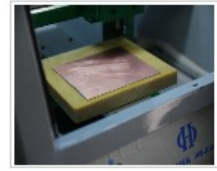

9

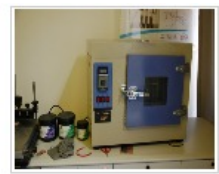

化学制板

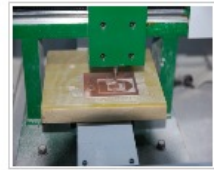

6

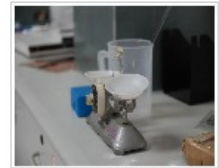

10

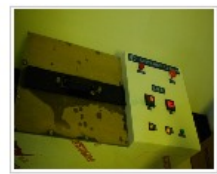

恶影㚮

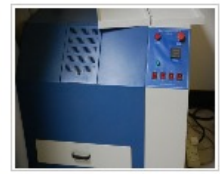

7

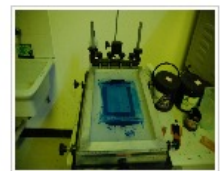

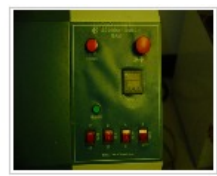

来光机

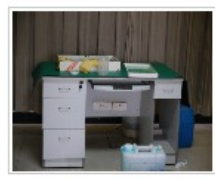

8

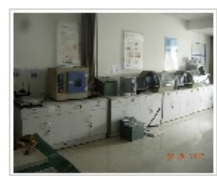

Fig. 2 Equipments for electronic engineering training

During the last two weeks of the freshman summer break, "Opto-mechanical Structure Design" course is arranged. In this course, the students learned to design a simple opto mechanical structure independently, and completed a simple project design. By completing this project design, students had the opportunity to learn how to use general mechanical design software, such as SolidWorks, to carry out real mechanical structure design.

Compared to freshmen, sophomore students have already learned some introductory courses about optics and electronics. Students are willing to try their own ability to see what they can actually do after two years of study. At this point, a design project that matches students' abilities is arranged to apply their knowledge to practice. By such design practices, students can learn how to use theoretical knowledge in practical application.

\subsection{Engineering training}

"Engineering training" is a general program for all of students, not only for optical engineering majors. The usage of various mechanical tooling such as turning machine, miller, grinder etc. will be trained in this program. It is not a key part of Education and Training in Optics and Photonics (ETOP). We will explain the implementation of the hierarchy curriculum in detail except for "engineering training".

\subsection{SRTP}

SRTP is open to students who have the desire and ability to pursue project research. The project can be proposed by the students themselves or by faculty members of the college.

In the beginning, students will select from the project list proposed by the teachers. Then, they will prepare a project implementation plan. They will then present their project implementation plan, which will be reviewed by faculty members. Mentors and team members discuss the project progress regularly. Lastly, a demonstration and presentation of project research results will graded. The college provides about 1000 RMB for each team, and the advisors usually give additional finance support. More than $80 \%$ of students participate in SRTP, and about $90 \%$ of them can pass the final presentation and obtain non-lecture credit.

\subsection{Electronic Engineering Training}

Electronic Engineering Training practice is an electronic circuit-based practicum course. Circuit design and debugging are basic skills that students who are electrical related majors must master. The electronic engineering training practicum involves schematic drawing, PCB layout, PCB engraving, welding, debugging and other exercises. The course pays attention to hands-on training, assisted with some theoretical material to improve the student's hands-on ability and foster teamwork spirit. 


\subsection{CAD based optical system design}

The course on CAD based optical system design is set in the second summer break. Students have finished the course "Applied Optics" after the end of their sophomore year. We schedule the optics system design course two weeks after summer break. This course lets students learn how to use Zemax, an optics design software commonly used in industry, to design typical telescope and microscope lenses.

\subsection{National University Students' Optical-Science-Technology Competition}

Competition Games are very attractive to young students. In the past decades, there are no specific competition games for optical and photonics engineering students. In order to inspire enthusiasm for learning optics in the students, ZJU has found the National Optical Design Competition Game for College Student in 2008. The $5^{\text {th }}$ game was held in University of Electronic Science and Technology in Chengdu, China. More than 700 students from 80 universities joined the game.

\subsection{Junior Year Off-Campus Externship}

Students in other countries find practicum companies are entirely students own business. If they want to get a good position, they must stand out from many applicants. They also handle living and traveling issues on their own. In some ways, Chinese higher education are very lenient to students. Students can ask for help at any time. The university arranges almost everything for the students. Regarding practicums, students hope that the university can provide them with the best practicums.

Although the practice inside the university is more consistent with the students' professional knowledge background and abilities. The teachers and assistants during the practicum are all available fulltime to instruct students to solve the difficulties encountered in their practicum. From the perspective of professional counterparts, the school can meet the students' need in knowledge and technical training. But the practicums are specially constructed for students, not the real working world. The environment outside the practicum is an experience the school cannot provide.

To ensure every student have a chance to work in companies as an externship, teachers who are in charge take advantage of alumni resources. More than 20 optical and photonics related firms have agreed to serve as student internship camps. Every junior year student has opportunities to go to one of these firm to participate in the camp. These firms include Changchun Institute of Optical, Fine Mechanics and Physics, Chinese Academy of Sciences (CAS), Shanghai Institute of Optical, Fine Mechanics, CAS, Institute of Optics and Electronics, CAS and other high level research organizations, well-known companies, private enterprise and other types of technology companies.

Through internships in the enterprise, students experience a totally different atmosphere from that in school. Many students who participated mentioned that to effectively utilize these opportunities in the firm, self-motivation is very important. If one does not take the initiative, no one will care whether one studies. One must integrate itself into the organization before one can play its individual role. This way of doing things is completely different from that in school. At school, the teacher always considers the students' convenience. In firms, students will feel the need to relocate their position. The living condition during the off-campus internship is not as good as that on campus, but training students to adapt to industrial environments is very important. In order to enable students to be familiar with diverse enterprise environments, we also arrange students in two different enterprises to switch positions regularly, so each student may have the chance to work in two different enterprises. 


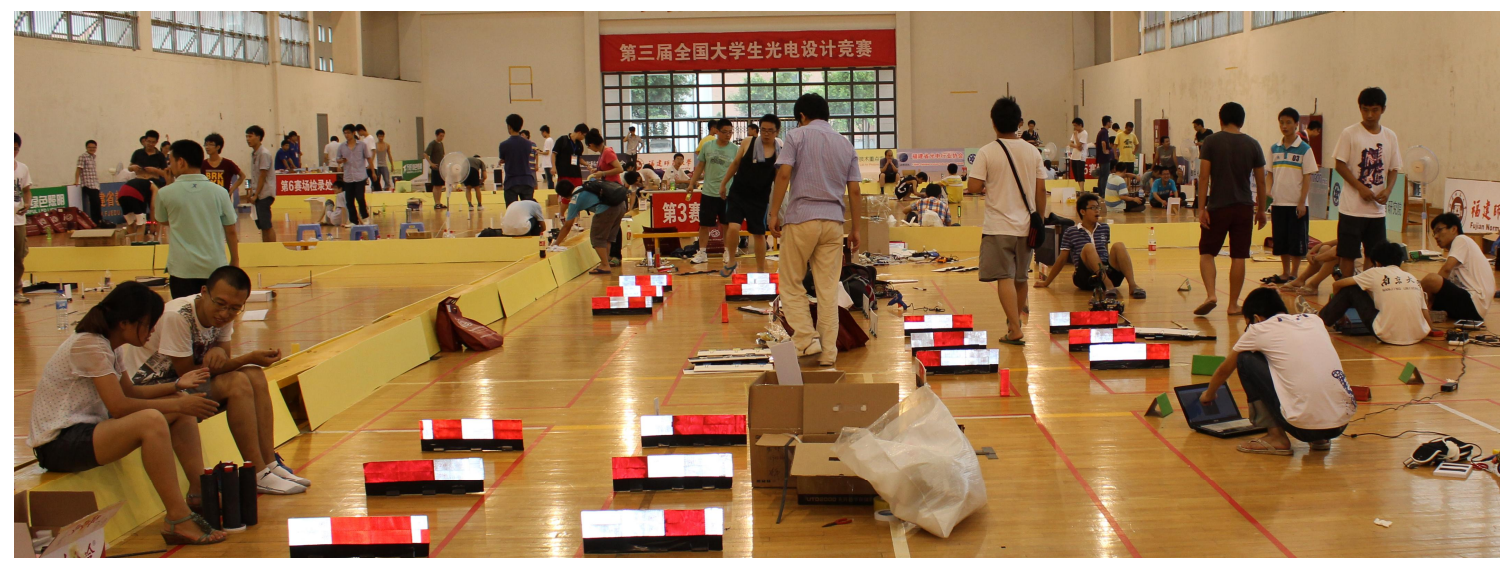

Figure 3. A scene of 3th NUSOSTC in Fuzhou. The students were preparing for the self-navigation car chasing competition.

\section{IMPLEMENTATION RESULTS}

After three years of implementation, the results are better than our expectations. The results can be seen in the following areas:

\section{The Students' Full Potential were Realized}

In a number of practicum sessions, students show extraordinary enthusiasm and exceptional talent. For example, in SRTP section, students had done a lot of in-depth reading in their research subjects. The students' understanding of the optics and photonics major had deepened remarkably.

2. Students could take advantages of their different specialties

This program shows that examinations in the educational evaluation system cannot comprehensively measure the overall quality of students. In practicums, the practice content is more diverse, therefore students can take advantage of their different specialties.

3. The students' abilities to apply knowledge were enhanced

Through these enhanced practicums, students had the opportunity to use knowledge learned in lectures to complete an actual project design. The application of theoretical knowledge in the project had deepen the students' understanding of knowledge greatly and helped student to build their own ability to apply knowledge into application.

4. Students were clearer about future career planning

After the internship, the workplace environment provided a clear reference for students for their career planning, and students cherished the learning opportunities in college more.

\section{CONCLUSIONS}

Through this hierarchy curriculum program, students apply, refine, and synthesize the knowledge, technique, and skills learned in the classroom. The focus point of this educational reform is summer practicums. By planning and constructing this practice system, we hope to improve the following problems: the students' confusion of the future in the profession, insufficient study initiative, the inability to apply theoretical knowledge in practice, and the long-standing teaching problem. After 3 years of practice and improvement, a summer practicum education system has been set up. Through these reforms, a set of implementation approach, practicum content and management system has been accumulated.

\footnotetext{
*xiaodongzheng@zju.edu.cn; phone/fax 86571 8795-1681
} 